\title{
Accounting Measuring - Rod For Buisnesses On Their Benefits To Society
}

\author{
Onuma . E. Onuma \\ Department of Accountancy, /Abia State Polytechnic Aba, Abia State, Nigeria
}

\begin{abstract}
Banks in Nigeria are laying off staff resulting in shoddy services due to inadequate staff. Also the Federal Government of Nigeria inundated with an already high unemployment number $(12.1 \%$ and $21.5 \%$ for youths) is worried and urging banks to reduce the layoff rate. A school of thought (Onuma, 1979), canvasses that provisions of Employment should be deemed a corporate social responsibility for as long as it can afford it. Based on the afore-stated, there is need to examine some big banks in Nigeria to determine whether they have been forth - coming in meeting their obligations to the society in providing adequate level of employment via a vis their respective earnings. A measuring-rod was derived and used for the assessments. Motown Corporation (USA) had a mixed result over 3 - year period. The six (6) Nigerian banks showed a mixed result too. 50\% scored below par in performance. This was in regard to their employment provision obligation.
\end{abstract}

Keywords: Earnings, Employment, Labour expenses, Measuring - rod, Social responsibility.

\subsection{Nature and Scope of Study}

\section{Introduction}

Recent time has seen the resurgence of a proposal put forward several decades ago that there is a "social audit" for businesses. This proposal represents a new school of thought in accounting. Which holds the view that businesses should report periodically their contributions to societal benefit; along with the traditional statements of financial position and operations. ${ }^{1}$

Ever since its proposal, the idea has been dormant for a number of reasons among which is what Dr. George A. Steiner (1972) describes as follows:

“...social audit, social accounting, or social accountability imply an arithmetical or quantitatively measuring evaluation. Such precision does not and probably cannot exist with respect to measures of social performance. $" 2$

This opinion of Dr. Steiner is not attempting to dismiss the relevance of social accounting/audit, but serves to point out the implicit need for a measuring device therein.

This relevance of social audit is even shown recognition by no less business figure than David Rockefeller (1971) when he says:

“... I can foresee the day when in addition to the annual financial statement, certified by independent accountants, corporations may be required to publish a "social audit" similarly certified ${ }^{3}$

Currently, certain social groups among others, such as Ralph Nader's organization, Council of Economic Priorities, the National Association of Concerned Business Students, National Urban League, have in various ways been measuring business contributions to societal benefits or woes. For example, such benefit as number of minorities and women employed is measured to test a company's compliance with affirmative action.

\subsection{Problems Specifically Involved:}

Accepting the idea of a social audit, one is confronted with the problems of determining the limit of contributions to societal benefits. In other words, how much contribution is enough?

Even after determining the upper and lower limits of contribution, there would arise the need to know what treatment to be given those who exceed the upper limit, i.e., contributed more than is required of them. Should they be allowed to stop contributing? Etc. 
Such problems mentioned above are reflected in the recent (1979) court decision against sears on Affirmative Action ${ }^{4}$. The case could be interpreted to involve a situation where a business entity believes it is doing "enough" for society (Minorities), but is being over pressured to do more than that.

Also, currently (1979) a fragment of southern Christian Leadership Conference (Atlanta Chapter) under State Representative Hosea Williams, is holding a campaign of customer boycott on Church's Fried Chicken in Atlanta. Below is an excerpt from the demand they are making on church's Chicken.

“... Due to the fact blacks buy $80 \%$ of Church's Chicken (White folks buy only $20 \%$ ), we demand that church's do $50 \%$ (not $80 \%$ they are entitled to), but only $50 \%$ of their buying from Black contractors build $50 \%$ of their new stores and refinish $50 \%$ of their old stores." 5 a

In defense, church's Fried chicken says they "contribute to Ebenezer Baptist Church, professional Athletes' Wives, Atlanta Hawks Photo Night, V - 103 Disco, support United Nergo College Fund, and had Life Memberships in SCLC and the NAACP (\$500 for Life)." $5 \mathrm{~b}$

\subsection{Study Concentration:}

In view of the foregoing, this study will seek to derive a means of measuring business standings in contributions to societal benefit relative to their growth rates.

\subsection{Study Significance}

The result of the study is aimed at being employed to resolve issues (controversies) such as is confronting Churches currently. Specifically, the application of the study results would help determine whether Church's has contributed "enough" to the society (Black populace) in terms of employment.

1.4.1 Sub - Problems Involved:

The Pursuit of this study calls for solving three sub - problems, Viz:

(a) The development of a rod for measuring social benefits

(b) The difficulty of quantifying certain societal benefits

(c) Ensuring universal applicability of the measuring rod derived in (a) above.

Commencing in solving these problems, we are constrained to espouse a working theory that observed linkage between Employment and Earnings. This is shown in SECTION II

\section{Section B}

\subsection{Theory of the Relationships among Labour Sales and Number of Employees Engaged}

2.1.1 As labour expenses get increasingly bigger, there would be a tendency for a business entity to cut back costs which could be done through the following ways:

(1) Lay - offs

(2) Firings

(3) Refusal to hire new employees

Logically then, in the long run, labour expense would be inversely related to number of employees engaged. Mathematically stated:

$$
\mathrm{L}=\frac{1}{e} \cdot \mathrm{k}
$$

Where $\mathrm{k}$ is a constant, $\mathrm{e} \neq 0$; $\mathrm{e}=$ no. of employees

$$
1=\text { labour expenses per hour }
$$

2.1.2 On the other hand, as sales increasingly get bigger, there would be the tendency for the business entity to hire more employees.

Logically then, in the long run, sales would be directly related to number of employee engaged.

Mathematically put,

$$
\mathrm{S}=\mathrm{ek}
$$


Where $\mathrm{k}$ is a constant, $\mathrm{e}=$ no. of employees

$$
\mathrm{S}=\text { annual sales. }
$$

2.1.3 By ratio principles, equations (1) and (2) can be combined as follows:

$$
\begin{aligned}
& \mathrm{L}: \mathrm{S} \text { as } \frac{1}{e} . \mathrm{k}: \mathrm{ek} \\
\therefore \quad & \quad \underline{\mathrm{L}}=\frac{1 / \mathrm{e} \cdot \mathrm{k}}{\mathrm{ek}}=\frac{1}{\mathrm{e}^{2}} \\
\therefore \quad & \mathrm{S}=\mathrm{L} \cdot \mathrm{e}^{2} \ldots \ldots \ldots \ldots \ldots \ldots \ldots
\end{aligned}
$$

2.1.4 From equation (3) the following conclusion is made:

In the long run, the Annual Sales of a business entity would tend to be related to its labour expenses per hour, and to the square of its number of employees.

\subsection{Hypothesis}

If the Annual Sales level is known and the labour expenses per hour for a given business entity, the expected number of employees are, can be determined as follows:

EXHIBIT I

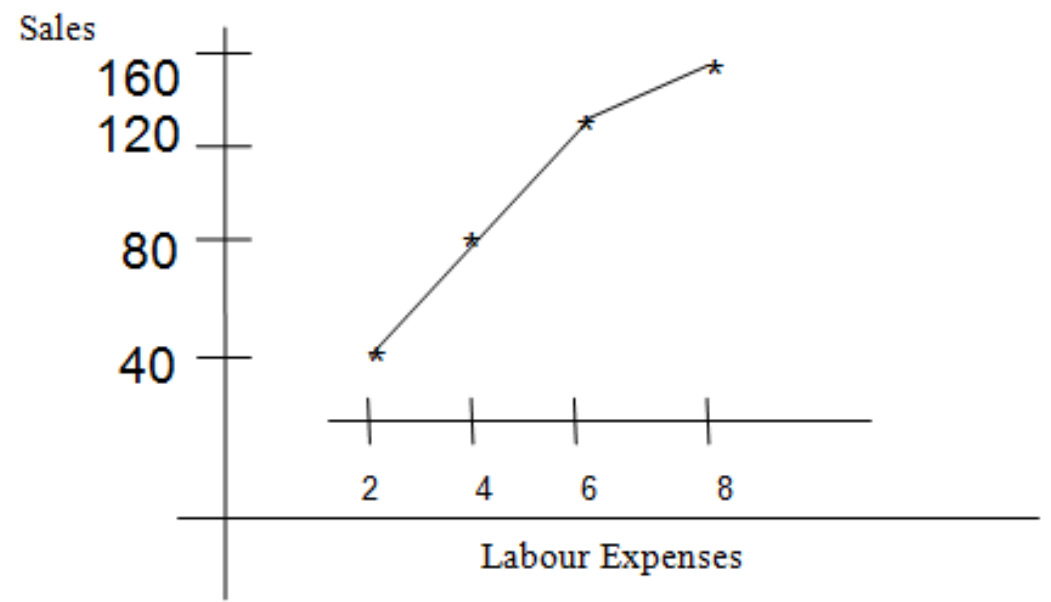

Graph of Annual Sales against Labour Expenses

Gradient of connecting line $=\mathrm{e}^{2}$

$$
\begin{aligned}
S=L . e^{2} \\
\therefore S / L=e^{2} \\
\therefore . " e "=\sqrt{ }(S / L)=\sum e
\end{aligned}
$$

Equation (4) constitutes the following:

(a) The hypothesized number of employees a company is expected to have;

(b) The test statistic needed to examine if a company's actual performance level varies from the hypothesized, expected level.

\subsection{Definition Of Relevant Terms}

2.3.1 Sales (5): The sum total of incomes realized from operations over a given period.

2.3.2 Labour Expenses per Hour (L) - Labour expenses per hour on one worker for one work year.

2.3.3 Number of Employees (e) - The sum total of wage earners engaged by a business entity.

2.3.4 Long Run - For the purpose of this study, long run is a representation of number of periods infinitely large.

2.3.5 Business Entity - An organization constructed for profit - making among other objectives. 


\subsection{Limitations Of The Test Statistics}

While the test statistic would prove useful in measuring the degree of a given company's contribution to employment, following limitations are discernible:

(a) It could not measure the quality of merchandise sold (i.e, whether beneficial or non-beneficial to society)

(b) It could not be used when $\mathrm{e}=0$ (i.e, when the given business entity has no employees).

Reason: $\quad$ Since $\mathrm{S}=\mathrm{Le}^{2}$

$$
\text { Then } \mathrm{S} / \mathrm{e}^{2}=\mathrm{L}
$$

If $\mathrm{e}=0$ then the left hand side of the equation becomes intermediate namely $\frac{s}{\text { zero }}$

\subsection{Procedure for Applying the Test}

\section{Section C}

3.1.1 In order to test a company's degree of contribution to societal benefit, such as employment, the following steps constitute the 'sesame':
3.1 .2
Base Year

Step I:

Pick a base year and state it e.g, $19 \times 1$.

Step II: Compute the hypothesized value of the number of employees.

Expected of a given company, based on equation (3) formula:

$" \mathrm{e}_{1} "=\sqrt{ }(\mathrm{S} / \mathrm{L})=\sum \mathrm{e}_{1}$, for the base year selected in step 1 .

Step III: Compare actual value of $\mathrm{e}_{1}$ as found from company personnel records with the hypothesized value $\sum \mathrm{e}_{1}$, computed in Step 1.

Step IV: Based on the comparison carried out in Step III above, draw a conclusion as to whether company's contribution is:

(a) At par with $\sum \mathrm{e}_{1}$

(b) Below $\sum \mathrm{e}_{1}$

(c) Above $\sum \mathrm{e}_{1}$

Step V: Classify company as follows:

If the result in Step III shows that the company's contribution level is of category (a) or (c), then it is classified as either "not under - contributing"; given that $\mathrm{e}_{1}=\mathrm{e} 1$ or

"over contributing"; given that $\sum \mathrm{e}_{1}<\mathrm{e}_{1}$.

On the other hand, if the company's contribution is of category (b) in Step III, then it is classified as: "under contributing". i e $\sum \mathrm{e}_{1}>\mathrm{e}_{1}$

\subsubsection{Year following Base Year}

Step I- B State the year immediately following the base year (19 x 1) selected in Base Year. In this case, it would be $19 \times 2$.

Step II- B Determine the percentage increase in sales between end of the base year (December 31, $19 \mathrm{X}_{1}$ ), and the end of the year that comes immediately after the base year (December 31,19x2), as follows:

Increase in Sales

Sales figure of base year $\mathrm{x} 100 \%$

Step III- B with the percentage figure determined in step II-B, $\sum \mathrm{e} 1$ namely the expected increase in $\sum \mathrm{e}_{1}$ (i.e., company's social responsibility) - based on sales growth - is computed as follows:

$$
\triangle^{e}=\left(\% \text { sales growth between end of Hypothesized } 119 \times 1 \text { and 19x2) } \times \sum \mathrm{e} 1\right)
$$

Step IV-B Add $\sum \mathrm{e}+\sum \mathrm{e} 1$ to compute the total number employees expected for the current year, namely $\sum \mathrm{e}_{2}$ 'i.e.,

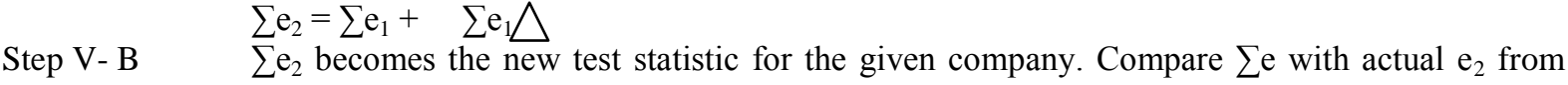
company personnel records and draw conclusion, accordingly.

Step VI- B Classify the company along the same pattern as was used in Base Year.

Note: Should one decide to carry on the test to subsequent year, 19x2 becomes the base year for 19x3; 19x3 the base year for " $19 \mathrm{x} 4$; etc.

\subsection{Data Source}

Note: Data are based on exhibit II: Ten (10) leading African American Enterprises in the USA test.

3.2.2(c) Company chosen to be tested from Exhibit I is Motown Industries. 


\subsection{Examples of the Test Application}

\section{Section C}

It is assumed that the average rate paid to each employee is equal to federal government's stipulated minimum wage, as follows;

$1976-\$ 2.30 / \mathrm{hr}$.

$1977-\$ 2.30 / \mathrm{hr}$.

1978 - \$2.65/hr.

We shall now utilize the formula to test leading African American Corporation including Motown and others.

\subsection{Test of Motown Corporation}

4.2.1 Step I: Base Year $=1976$

Step II: Compute hypothesized value of number of employees:

$$
\sum \mathrm{e}_{1}=\sqrt{ }\left(\frac{S}{L}\right)=\sqrt{ } \frac{50,000,000}{(2.30)(300)}=269
$$

Step III: Compare actual $\mathrm{e}_{1}$ with $\sum \mathrm{e}_{1}$

$$
300 \text { Work days Estimate }
$$

Actual $\mathrm{e}_{1}=300$ (from Exhibit I)

$$
\sum \mathrm{e}_{1}=269=\text { par }
$$

Conclusion: Motown's contribution to employment in 1976 is above par.

Step IV: Classify Motown based on conclusion drawn in Step III.

$$
\begin{aligned}
& \text { Actual } \mathrm{e}_{1}=300 \\
& \quad \sum \mathrm{e}_{1}=\underline{269} \\
& +31 \text { employees (Motown's “over-contribution") }
\end{aligned}
$$

4.3 Step I- B: Year immediately after $=1977$

Step II- B: Determine percentage increase in sales between December 31, 1976 and December 31, 1977.

$=\underline{\$ 61.4 \text { million minus } \$ 50 \text { million }}=\underline{11.4}=22.8 \%$

$$
\$ 50 \text { million } \quad 50
$$

Step III- B: $\quad$ Compute $\quad \sum \mathrm{e}_{1}=ð 2.8 \%$ of $269=61.3$, i.e., 61

Step IV-B: $\quad$ Compute $\sum \mathrm{e}_{2}=\underset{\substack{\sum \\=251+61=312}}{\sum \mathrm{e}_{1}+\mathrm{e}_{1} \bigwedge}$

Step V-B: $\quad$ Compare $\sum \mathrm{e}_{2}$ with actual $\mathrm{e}_{2}$

$$
\begin{aligned}
& \text { Actual } \mathrm{e}_{2}=300 \\
& \sum \mathrm{e}_{2}=312-\text { par }
\end{aligned}
$$

4.4 Observation: Motown's contribution to employment for 1977 is below par.

Step VI- B: $\quad$ Classify Motown:

$$
\begin{aligned}
& \text { Actual } \mathrm{e}_{2}=300 \\
& \sum \mathrm{e}_{2}=\frac{312}{01} \quad \begin{array}{c}
\text { Motown's } \\
\text { "under - contribution" } \approx-12
\end{array}
\end{aligned}
$$

Step I- C: $\quad$ Year immediately after $=1978$

Step II- C: Determine percentage increase in sales between December 31, 1977 and December 31, 1978.

$=\underline{\$ 58 \text { million minus } \$ 61.4 \text { million }}=\underline{-3.4}=-5.53 \%$

$$
\$ 61.4 \text { million } \quad \frac{-3.4}{61.4}
$$

Step III- C:Since Motown sales fell from \$61.4 million in 1977 to \$58 million in 1978, the expected change in number of people employed will be negative. That means Motown is entitled to layoff some employee if need be. The computation of the decrease goes as follows:

$$
\text { - } \quad \sum \mathrm{e} 2=-5.53 \% \text { of } 312 \triangle
$$

-17 (possible no. to be laid off)

Step IV- C: $\quad$ Compute $\sum \mathrm{e}_{3}$

$$
\sum \mathrm{e}_{3}=-\triangle \sum \mathrm{e} 2=\sum \mathrm{e}_{2}=-17+312=295
$$


Step V-C: $\quad$ Compare $\sum \mathrm{e}_{3}$ with $\mathrm{e}_{3}$

Actual $\mathrm{e}_{3}=300$

$\sum \mathrm{e}_{3}=300-295$ (over contribution)

4.5Observation:

Motown's contribution to employment for 1978 is above par.

Step VI- C: $\quad$ Classify Motown Industries' contribution for 1978.

Actual e3 $=300$

$\sum \mathrm{e} 3=295$

employment (Motown's “over-contribution)

\subsection{Exhibit III Motown's Score Card On Contributions To Employment}

Year

1976

Over-contributed (+)/ Under-contributed

1977

1978

$-12$

$+5$

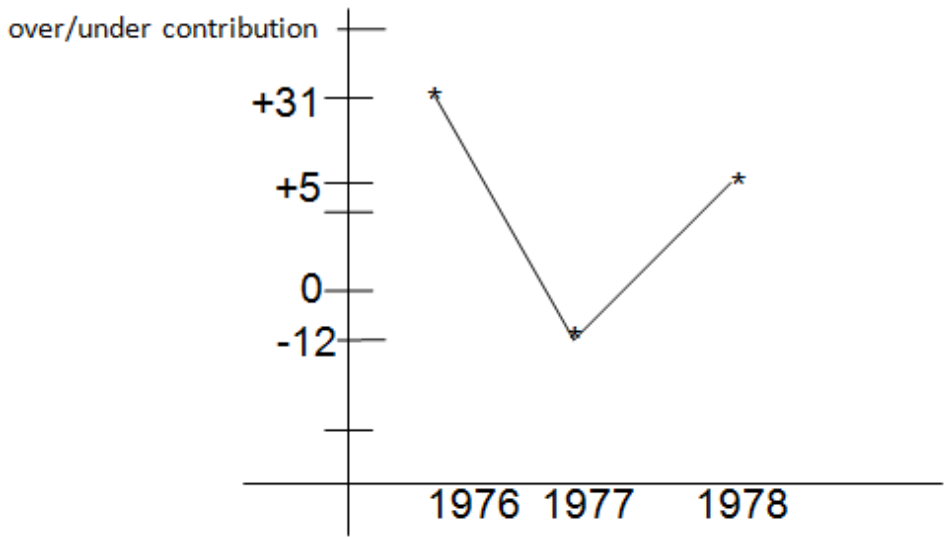

\subsection{Exhibit iii}

Observation: Contribution is shaped concave up

Sales

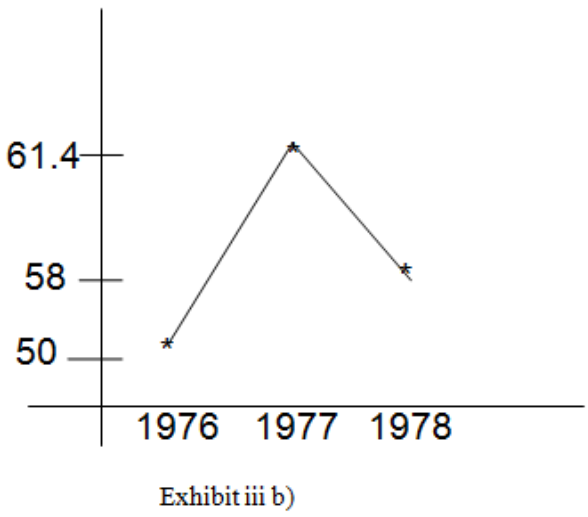

Observation: Contribution is shaped concave up

\subsection{Overall Evaluation of Motown's Contribution}

On the score card, the figures revealed that Motown is quite "above par" in contributions to societal benefit. However, the graphical representation of sales in the three-year period and over/under-contributions in the same period (see exhibit III) reveal a number of factors worth taking into consideration in evaluation of Motown. These are:

(1) Motown had a comparatively low sales figure in 1976 but a comparatively high over-contribution; then,

(2) In 1977, though sales increased by as much as $22.8 \%$, Motown under-contributed to employment.

(3) In 1978, the sales figure fell by about 5.53\% yet Motown increased its contribution to attain "above par" status. In view of the foregoing, Motown could be said to be contributing its fair share to societal benefit in terms of fighting unemployment. Now, this is not an absolute statement. 
4.9 Alternative Measure for $\square(\mathrm{S} / \mathrm{L})$

$\sqrt{ }(\mathrm{s} / \mathrm{l})$ could be adjusted using the average measure of $\mathrm{L}$ which is $\frac{\text { Zero }+\mathrm{L}}{2}=\frac{\mathrm{L}}{2}$

Therefore, bipolar measure for expected number of employees $\left(\sum \mathrm{e}\right)$ would be:

$\sqrt{ }(\mathrm{S} / \mathrm{L}) \geq \sum \mathrm{e} \leq \sqrt{(\mathrm{s} / 1 / 2 \mathrm{~L})}$

Where " $x$ " is actual number of employees which is expected to fall between the two measures namely: lower limit and upper limit respectively. Based on the foregoing, we can now redo the test for Motown Corporation USA at the base year.

Lower Limit $=269$ as computed before

Upper Limit $=\sqrt{ }(50000000 / 2.30 \times 300$ days/2) $=381$

Therefore the acceptable range for Motown Corporation USA is:

L: $269 \leq \mathrm{x} \leq 381$

If it falls below the range, Motown would be sanctioned accordingly. But if it falls above the range, it should be justified to receive tax credit based on yet to be determined mode.

It is suggested to the reader to test other companies in Exhibit I along the lines followed for Motown. This would enable him or her to evaluate the level of contribution ascribable to each.

\section{Section D}

5.1 Validation of the Theory on Measuring Rod's Basis Using Regular Hypothesis Testing Techniques Namely:

(i) Correlation and Regression

(ii) Student t statistic

\subsection{Hypothesis}

$\mathrm{H}_{0}$ : The number of employees is not dependent on sales

$\mathrm{H}_{1}$ : The number of employees is dependent on sales

\subsection{Step I: Correlation determination (Employees Vs Sales)}

TABLE 5.3.1

\begin{tabular}{|l|l|l|}
\hline S/NO & 3 -Year Average No. Of Employees & 3-Year Average Sales $(\$ \mathrm{M})$ \\
\hline 1 & $\frac{300+305+300}{3}=300$ & $\frac{50+61.4+58}{3}=57$ \\
\hline 2 & $\frac{320+395+462}{3}=392$ & $\frac{47.6+50.2+55.6}{3}=51$ \\
\hline 3 & $\frac{450+525+550}{3}=508$ & $\frac{37+45+48}{3}=43$ \\
\hline 4 & $\frac{413+437+532}{3}=461$ & $\frac{43.5+38+41.1}{3}=41$ \\
\hline 5 & $\frac{300+150+150}{3}=200$ & $\frac{21+25+32}{3}=26$ \\
\hline 6 & $\frac{42+78+44}{3}=55$ & $\frac{13.5+14.5+16.5}{3}=15$ \\
\hline 7 & $\frac{56+50+67}{3}=58$ & $\frac{12.1+13.9+15.5}{3}=14$ \\
\hline 8 & $\frac{60+71+75}{3}=69$ & $\frac{11.4+12.7+11.7}{3}=13$ \\
\hline 9 & $\frac{36+52+35}{3}=41$ & $\frac{5.1+6.8+9.1}{3}=7$ \\
\hline 10 & $\frac{63+152+153}{3}=123$ & 283 \\
\hline Totals & \multicolumn{2}{|l|}{$=16$} \\
\hline
\end{tabular}

5.3.2 Let number of Employees $=\mathrm{X}$

5.3.3 Let Sales $(\$ M)=Y$ 


\section{TABLE 5.3.4}

\begin{tabular}{|l|l|l|l|l|l|}
\hline S/NO & $\mathbf{X}(\mathbf{E M P L O Y E E S )}$ & $\mathbf{Y}(\mathbf{\$ M})$ & $\mathbf{X Y}$ & $\mathbf{X}^{\mathbf{2}}$ & $\mathbf{Y}^{\mathbf{2}}$ \\
\hline 1 & 300 & 57 & 17100 & 90000 & 3249 \\
\hline 2 & 392 & 51 & 19992 & 153664 & 2601 \\
\hline 3 & 508 & 43 & 21844 & 258064 & 1849 \\
\hline 4 & 461 & 41 & 18901 & 212521 & 1681 \\
\hline 5 & 200 & 26 & 5200 & 40000 & 676 \\
\hline 6 & 55 & 16 & 880 & 3025 & 256 \\
\hline 7 & 58 & 15 & 870 & 3364 & 225 \\
\hline 8 & 69 & 14 & 966 & 4761 & 196 \\
\hline 9 & 41 & 13 & 533 & 1681 & 169 \\
\hline 10 & 123 & 7 & 861 & 15129 & 49 \\
\hline & 2207 & 283 & 87147 & 782209 & 10951 \\
\hline & $\#$ & $\mathbf{\$ M}$ & & & \\
\hline
\end{tabular}

$$
\text { 5.3.5 } \frac{\mathrm{r}=\quad \underline{\mathrm{n} \sum \mathrm{xy}-\sum \mathrm{x} \sum \mathrm{y}}}{\sqrt{\left.\mathrm{n}\left(\sum \mathrm{x}^{2}\right)-\left(\sum \mathrm{x}\right)^{2} \mathrm{x}\left(\mathrm{n} \sum \mathrm{y}^{2}\right)-\left(\sum \mathrm{y}\right)^{2}\right)}}
$$

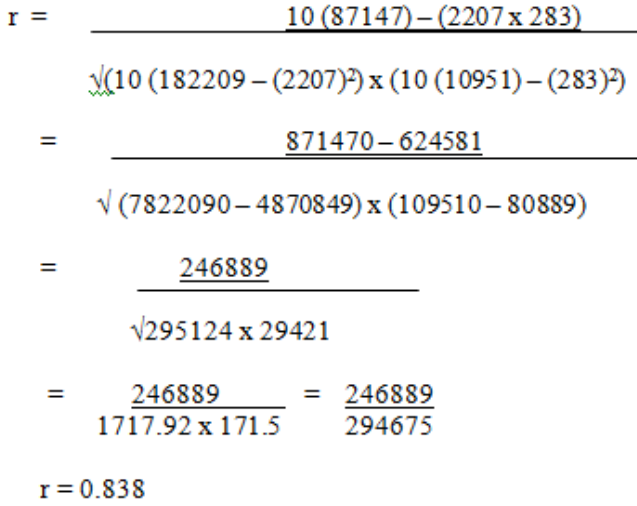

Interpretation

Since $r$ is such that $-1 \leq r \leq 1$

For $\mathrm{r}=0.838$, the correlation is enormous and positive

\subsection{Step II: Regression Line Determination}

$\mathrm{Y}=\mathrm{a}+\mathrm{bx}$

5.4.1 Where $a=Y-b x(Y=$ mean of $\bar{Y}, \bar{X}=$ mean of $X)-$

5.4.2 $\quad \mathrm{b}=\frac{\mathrm{n} \sum \mathrm{xy}-\sum \mathrm{x} \sum \mathrm{y}}{\mathrm{n} \sum \mathrm{x}^{2}-\left(\sum \mathrm{x}\right)^{2}}$ $\mathrm{n} \sum \mathrm{x}^{2}-\left(\sum \mathrm{x}\right)^{2}$

5.4.2 From the data

$$
\begin{aligned}
\mathrm{b} & =\frac{(10(87147)-(2207)(283)}{10(782209)-(2207)^{2}} \\
& =\frac{871470-624581}{7822090-4870849} \\
\mathrm{~b} & =\frac{246889}{295124}=0.084
\end{aligned}
$$

Also

$$
\begin{aligned}
& a=\bar{y}-\overline{b x} \\
& a=(\text { Mean Y })-b(\text { mean } x) \\
& a=\frac{283}{10}-b \frac{2207}{10}
\end{aligned}
$$


$=28.3-0.084(220.7)$

$28.3-18.54=9.76(10$ approximately $)$

\subsubsection{Regression Line Equation}

$\mathrm{Y}=\mathrm{a}+\mathrm{bx}$

$Y=10+0.084 x$

Thus for any given Sales level (Y) in millions of Dollars we can predict $\mathrm{x}$ being the expected number of employees. And where the actual is less than predicted then the company is deemed to have failed in its social responsibility of providing proper employment. On the other hand if the Actual figure of employees surpasses the predicted (computed) value this indicates the company would be deemed to have met its corporate responsibility in providing appropriate employment.

\subsection{Student $t$ test statistic derivation}

$$
\begin{aligned}
\mathbf{t} & =\frac{\mathbf{r}}{\sqrt{\frac{1-r 2}{n-2}}} \\
& =\frac{0.838}{\sqrt{\frac{1-(.838) 2}{10-2}}} \\
& =\frac{0.838}{\sqrt{\frac{1-.702}{8}}} \\
& =\frac{.838}{\sqrt{.037}} \quad \mathrm{t}=4.36 \\
& =\frac{.838}{.192}
\end{aligned}
$$

5.5.2 For a two tail test at $5 \%$ risk level $=2.5 \%$ effectively (95\% confidence level) from the student t table the value $=2.776$ (i.e critical value)

Since computed $t=4.364$ is greater than critical value 2.776 . If is deemed significant.

Then the Null hypothesis $\mathrm{H}_{\mathrm{o}}$ must be rejected

The alternative Hypothesis $\mathrm{H}_{1}$ must be accepted i.e Number of Employees is dependent on sales

Observation: This is consistent with the basis of our thesis and measuring rod for corporate responsibility.

\section{Section E}

\subsection{Test For Some Major Nigerian Banks With Earnings Above N100 Billion Per Annum}

\subsubsection{Preliminary facts and procedure}

1. Minimum wage in Nigeria is N18, 000 per month based on eight (8) working hours per day and 365 days per annum.

2. This spells out as $\underline{\mathrm{N} 18000} \times 12$ months $=\underline{\mathrm{N} 216000}$

N73.97 per hour (approx)

$$
365 \times 8 \text { hrs } 2920 \mathrm{hrs}
$$

i. Workdays in Banks per year

Five days per week x 52 weeks

Less leave and holiday period

$$
\begin{aligned}
& =260 \text { days } \\
& \underline{(30)}
\end{aligned}
$$

Net works days per annum

ii. Since e $=\sqrt{ } \frac{S}{l} \quad$ based on our theory

(Where $\mathrm{S}=$ earnings, $\mathrm{L}=$ number employed, e = labour expenses). Therefore the acceptable range for $\sum \mathrm{e}$ (expected employees) is as hereunder: 
Lower limit

$$
=\sqrt{\frac{\text { Annual income }}{73.97 \times 230}}
$$

Upper limit

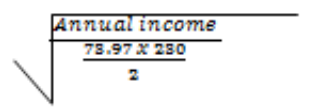

6.1.2 Here the denominator $\left(\frac{73.97 \times 230}{2}\right)$ is based on "Average". Valuation thus an acceptable limit for Nigerian Banks (or any other corporation) in the number of employment required is as hereunder:

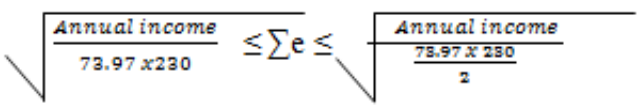

Where $\sum$ e represent expected number of employees. If actual (e) falls outside this range, it is unacceptable. Now we would apply this procedure on six(6) Nigeria's biggest bank with earnings of over N100 billion Naira per each annum, each.

\subsubsection{Guarantee Trust Bank Of Nigeria Plc (GTB)}

Determining the acceptable range of number of Employees in Payroll $\left(\sum \mathrm{E}\right)$

Annual Income 242 Billion Naira

$$
\begin{aligned}
& 6.2 .1 \text { Lower Limit }=\sqrt{\frac{242000000000}{73.97 \times 230}} \\
& \begin{array}{l}
\text { Upper Limit }=3772 \\
= \\
=
\end{array} \\
& =
\end{aligned}
$$

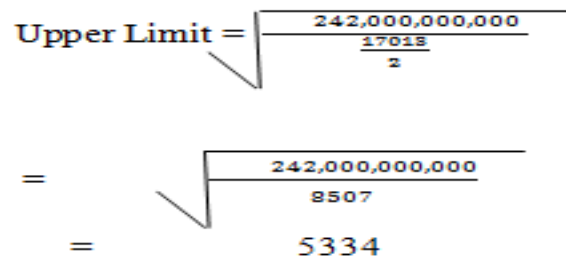

6.2 .3

a. $\quad$ GTB's range of acceptable number of employees is $3772 \leq \sum \mathrm{e} \leq 5334$

Actual number on payroll $=3500$

6.2.4 Decision

b. Since the lower limit is 3772 and the Actual is 3500 , then bank should be sanctioned and made to make up for the deficiency $(3722-3500)=272$

c. They should not be allowed to lay off any staff for now.

\subsubsection{Access Bank Plc}

Annual Income N207 Billion

Number of Employees 9000

Expected Employment $\sum$ e range
6.3.1 Lower Limit $=$
$\sqrt{\frac{207,000,000,000}{17013}}=3488$
6.3.2 Upper Limit $=$

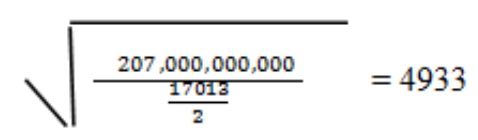

\subsubsection{Acceptable range}

$3488 \leq \sum \mathrm{e} \leq 4933$ 


\subsubsection{Decision}

a. $\quad$ Since the actual number of employees $=9000$

This falls above the upper limit, therefore the organization (Access Bank) should receive TAX CREDIT accordingly for the excess load $(9000-4933)=4067$

b. We should then over-look any action of lay-off for now as it appears justified. But any layoff should not surpass the excess load value.

\subsubsection{Eco Bank Plc}

Annual Income N177 Billion

Number of Employees 5000

Expected Employment $\sum$ e range

6.4 .2

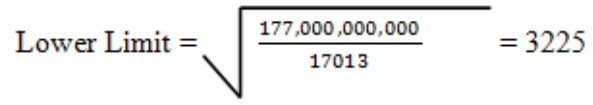

6.4 .3
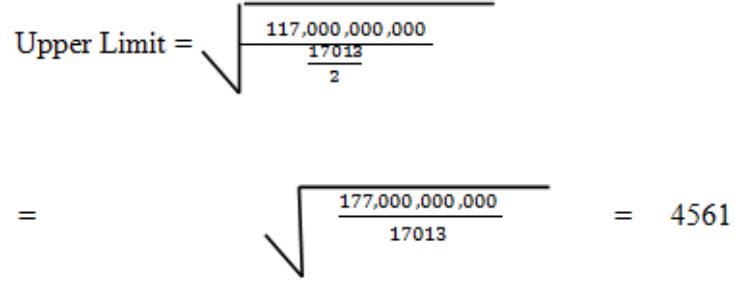

6.4.4 Acceptable range of Number in Payroll $3225 \leq \sum \mathrm{e} \leq 4561$

\subsubsection{Decision}

a. Since the actual number of employees $=5000$

This falls above outside the range and beyond the upper limit.

Therefore the bank deserves TAX CREDIT FOR THE EXCESS load of $(5000-4561)=439$

b. We should overlook any ECO bank's action in laying off some staff within the limits of the excess load value.

\subsubsection{Fidelity Bank Plc}

Annual Income 127,000,000,000 (N127)

Number of Employees 4000

Range of Acceptable number of Employees $\sum \mathrm{e}$ range

$$
\begin{aligned}
& \text { 6.5.1 Lower Limit }=\sqrt{\frac{127,000,000,000}{17013}}=2732 \\
& \text { 6.5.2 Upper Limit }=\sqrt{\frac{117,000,000,000}{\frac{17013}{2}}} \\
& =\sqrt{\frac{\frac{127,000,000,000}{8507}}{3864}}
\end{aligned}
$$

\subsubsection{Acceptable range}

$$
2732 \leq \sum \mathrm{e} \leq 3864
$$

\subsubsection{Decision}

1. Since actual number in payroll is 4000 . This lies slightly above the upper limit of 3864 . There appears to be an excess load of $4000-3864=136$

2. They should therefore receive TAX credit accordingly on the excess load.

3. Layoffs may be allowed up to the limits of the excess load value. 
6.6.0. Sterling Bank Plc

Annual Income: N92 Billion

Number of Employees 2285

Expected range of number on payroll $\left(\sum \mathrm{e}\right)$

6.6.1 Lower Limit $=$

6.6.2 Upper Limit $=$

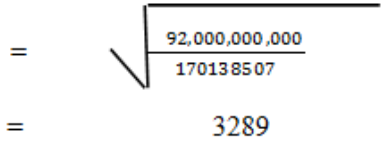

6.6.3 Acceptable range

$2385 \leq \sum \mathrm{e} \leq 3289$

6.6.4 Decision

a. Since number of employees falls outside the acceptable range and slightly smaller than the lower limit the bank should be sanctioned and encouraged to make up for the deficiency of $2325-2285=60$

b. The bank should not layoff any staff for now.

\subsubsection{First City Monument Bank (FCMB)}

Annual Income N131 Billion

Number of Employees 2000

Expected range of number in payroll $\left(\sum \mathrm{e}\right)$

6.7.1 Lower Limit $=\sqrt{\frac{131,000,000,000}{17013}}=2775$

6.7.2 Upper Limit $=\sqrt{\frac{131,000,000,000}{\frac{17013}{2}}}$

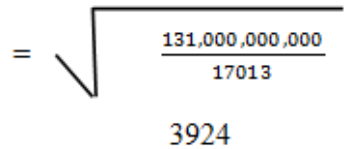

6.7.3 Acceptable range

$2775 \leq \sum \mathrm{e} \leq 3924$

6.7.4 Decision

a. Since actual number of employees is 2000 which falls outside the acceptable range and below the lower limit then the FCMB should be sanctioned accordingly and encouraged to make up the deficiency of 2775 $-2000=775$

b. It should not be allowed to layoff any staff for now

6.8 Summary of Six Nigerian Major Bank Contribution to Employment Test

TABLE 6.8.1

\begin{tabular}{|l|c|}
\hline Bank & Over/(under) Contribution \\
\hline Guarantee Trust Bank (GTB) & $(272)$ \\
\hline Access Bank & 4067 \\
\hline ECO Bank & 439 \\
\hline Fidelity Bank & 136 \\
\hline Sterling Bank & $(60)$ \\
\hline First City Monument Bank & $(775)$ \\
\hline
\end{tabular}


6.8.2 Proportion of financial institutions that over contributed

$$
\frac{3}{6}=50 \%
$$

6.8.3 Proportion of financial institutions that under contributed

$$
\frac{3}{6}=50 \%
$$

\subsubsection{Observation}

The percentage of those that under-contributed $(50 \%)$ is quite significant requiring further study on the other banks in Nigeria. This will be done using the same measuring rod utilized herein.

\subsection{Summary on Measuring Rod}

\section{VII.Section G: Conclusion}

This study aims at deriving a measuring rod to test the standing of businesses in terms of their contributions to any given societal benefit. Specifically, the societal benefit used in this study is employment. The test statistic derived is based on the hypothesis that

$$
\begin{aligned}
\mathrm{S}= & \mathrm{L} \cdot \mathrm{e}^{2} \quad \text { Where } \mathrm{S}=\text { Annual Sales Figure } \\
\mathrm{L} & =\text { Labour Expenses/Hour } \\
\mathrm{e} & =\text { No. of Employees in the year }
\end{aligned}
$$

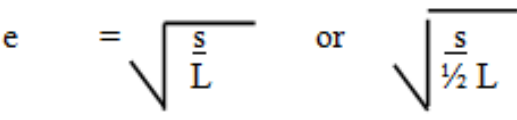

$$
\text { The acceptable range for } \mathrm{e}=\sqrt{\frac{\mathrm{s}}{\mathrm{L}}} \leq \sqrt{\frac{\mathrm{s}}{1 / 2 \mathrm{~L}}}
$$

Motown Industries was tested and found to be quite "above par" in contribution to employment for a three-year period covering 1976 - 1978. The test could be carried for any other company making use of the procedures in the study.

\subsection{Recommendation for further study}

1. Examining of "Fortune 500" corporations on whether each met its corporate social responsibility regarding employment score-cards.

2. Suggesting Tax credit regime for corporations that scored above par.

3. Suggesting sanctions regime for corporations scoring below par.

\subsection{Closing remarks}

Henceforth, employment is deemed a corporate social responsibility which is measurable employing a rod determined herein.

Our findings on Motown Corporation U.S.A are a mixed result. However, our findings on six major Nigerian banks (-with earnings of N100billion (Naira)) per annum, each showed also a mixed result. A significant proportion thereof (50\%) showed a below par performance.

\section{Acknowledgement}

I remain grateful to God who is the source of my strength. I also want to say a big thank you to Professor M.W.Glover of Atlanta University, Georgia U.S.A who served as an inspirational guide in the primary work done in this study.

I am deeply grateful to my wife and children.

\section{References}

[1]. Bowen H.R Society Responsibilities of the business Harper and brother N.Y 1953. (2)

[2]. Steiner George, A "should Business adopt Social Audit the conference Board (Academy of Management) U.S May 1972. (2)

[3]. Rockefeller, D." Address to the Advertising Council reported in the Los Angeles Times January 31, 1971. (2)

[4]. Sears Vs EEDC (court proceedings) U.S, 1979 (3)

[5]. [5a\&b]Metro Atlanta SCLC, Rev Hosea Williams "lease join our picket line today" a brochure published for the church boycott June 1979. (3)

[6]. U.S department of Labour, wages information Division 1976, 1977, 1978. (9)

[7]. Black Enterprises magazine type Top 100, June U.S, June 1977, June 1978, June 1979. (10)banksinNigeria 2016. (20)

[8]. Hoel, P.G. and Jenson, R.J. Basic Statistics for Business and Economics. John Wiley \& Sons. U.S. 1977. (15) 